\title{
A new isoform of interleukin-32 suppresses IL-8 mRNA expression in the intestinal epithelial cell line HT-29
}

\author{
HIROTSUGU IMAEDA $^{1}$, AKIRA ANDOH ${ }^{3}$, TOMOKI AOMATSU ${ }^{1}$, RIE OSAKI ${ }^{1}$, SHIGEKI BAMBA ${ }^{1}$, \\ OSAMU INATOMI $^{1}$, TOMOHARU SHIMIZU ${ }^{2}$ and YOSHIHIDE FUJIYAMA ${ }^{1}$ \\ Departments of ${ }^{1}$ Medicine, and ${ }^{2}$ Surgery; ${ }^{3}$ Division of Mucosal Immunology, Graduate School of \\ Medicine, Shiga University of Medical Science, Seta Tsukinowa-cho, Otsu, Shiga 520-2192, Japan
}

Received December 16, 2010; Accepted February 7, 2011

DOI: $10.3892 / \mathrm{mmr} .2011 .442$

\begin{abstract}
Interleukin (IL)-32 plays a role in the pathophysiology of inflammatory bowel disease (IBD). We isolated a new isoform of the IL-32 transcript in the process of cloning the full-length $I L-32$ gene from human colonic subepithelial myofibroblasts (SEMFs). The expression of mRNA in the samples was assessed by RT-PCR and real-time PCR analyses. The PCR products from the IL-32 genes were ligated into the expression vector pIRESneo2. The new isoform of the IL-32 transcript (336 nucleotides) completely lacked exon 4 of the $I L-32 \gamma$ gene, and was 60 bp shorter than IL-32 $\alpha$. TNF- $\alpha$ induced the mRNA expression of the new IL-32 isoform in a dose- and time-dependent manner. Stable transfection of this new isoform significantly decreased TNF- $\alpha$-induced IL- 8 mRNA expression in HT-29 cells, but the expression of the IL-32 $\alpha$ gene had no effect. The mRNA expression of this new isoform was significantly elevated in the inflamed mucosa of IBD patients. A new isoform of the IL-32 transcript may play an anti-inflammatory role in the inflamed mucosa of IBD.
\end{abstract}

\section{Introduction}

Interleukin (IL)-32 is a recently-described cytokine produced by $\mathrm{T}$ lymphocytes, natural killer cells, monocytes and epithelial cells $(1,2)$. Although IL-32 was first reported as a transcript in IL-2-activated NK and T cells, it appears that epithelial cells are the dominant and widespread source (3). The gene encoding IL-32 is located on human chromosome $16 \mathrm{p} 13.3$, and is organized into eight exons (4). There are four splice variants (IL-32 $\alpha$, IL-32 $\beta$, IL-32 $\delta$ and IL-32 $\gamma$ ). In addition, two more isoforms (IL-32 $\varepsilon$ and $\zeta$ ) have been reported, but

Correspondence to: Dr Akira Andoh, Division of Mucosal Immunology, Graduate School of Medicine, Shiga University of Medical Science, Seta Tukinowa, Otsu 520-2192, Japan

E-mail: andoh@belle.shiga-med.ac.jp

Key words: inflammatory bowel disease, tumor necrosis factor- $\alpha$, NOD2, HT-29 these have not been found to be abundantly expressed in cell types besides activated $\mathrm{T}$ cells (5). Although cytokine gene splicing events are unusual, they exist in other cytokines, such as IL-1F7 and vascular endothelial growth factor $(6,7)$. Of the six isoforms, IL-32 $\gamma$ is the longest and exhibits the highest biological activity in vitro and in vivo (8). IL-32 exhibits several properties typical of proinflammatory cytokines $(1,2)$; for example, it stimulates the secretion of proinflammatory cytokines and chemokines such as IL-1 $\beta$, TNF- $\alpha$, IL-6 and IL- 8 by the activation of $\mathrm{NF}-\kappa \mathrm{B}$ and $\mathrm{p} 38$ mitogen-activated protein kinases (MAPKs) $(1,2)$.

Ulcerative colitis (UC) and Crohn's disease (CD), two common forms of inflammatory bowel disease (IBD), are chronic relapsing inflammatory disorders of the gastrointestinal tract (9-11). IBD result from the inappropriate and ongoing activation of the mucosal immune system driven by the presence of normal luminal flora (9-11). Previously, Netea et al reported that IL-32 augments the production of IL-1 $\beta$ and IL-6 induced by muramyl dipeptide (MDP), a peptidoglycan fraction from bacteria, by means of nucleotidebinding oligomerization domain proteins (NOD1 and NOD2) through a caspase-1-dependent mechanism (2). NODs are a family of intracytoplasmic bacterial sensors, and the recognition of bacterial peptidoglycans subsequently induces $\mathrm{NF}-\kappa \mathrm{B}$ activation (12). Mutations in NOD2 have been implicated in the pathogenesis of $\mathrm{CD}(13,14)$, and $\mathrm{CD}$ patients homozygous for the frameshift 3020insC mutated allele have defective responses to MDP in terms of cytokine production $(9,15,16)$. Recently, it has been shown that the NOD2 mutation in CD patients potentiates $\mathrm{NF}-\kappa \mathrm{B}$ activity and IL-1 $\beta$ processing (17). Thus, these findings suggest a pivotal role for IL-32 in the pathophysiology of IBD $(18,19)$, and in particular CD.

Several studies have correlated IL-32 expression with IBD (18-20), and we previously reported that IL-32 expression by epithelial cells is increased in the inflamed mucosa of IBD patients (18). In our further investigation of IL-32 expression in the intestinal mucosa, we found a new isoform of the IL-32 transcript (336 nucleotides) through the process of cloning the full-length $I L-32$ gene from human colonic subepithelial myofibroblasts (SEMFs). Stable transfection of this new isoform of the gene into the intestinal epithelial cell line HT-29 suppressed TNF- $\alpha$-induced inflammatory responses. 
Table I. Primers used in this study.

Forward

TTGGCTCCTTGAACTTTTGG ${ }^{\mathrm{a}}$

IL-32 $\alpha, \gamma$, new isoform

(primers for cloning)

IL-32 new isoform

IL-8

$\beta$-actin
AAGCTGAAGGCCCGAATGGT

TGATTGAGAGTGGACCACAC

TGACCCAGATCATGTTTGAGACCT
Reverse

GCAAAGGTGGTGTCAGTATC $^{\mathrm{b}}$

GGCTCCGTAGGACTTGTCAC

CCAGGAATCTTGTATTGCAT

CCACGTCACACTTCATGATGATGGAG

${ }^{a}$ From -25 to -6 of the IL-32 $\gamma$ sequence; ${ }^{\text {bfrom }} 726$ to 727 of the IL-32 $\gamma$ sequence.

\section{Materials and methods}

Reagents. Recombinant human IL-6, IFN- $\gamma$ and TGF- $\beta$ were purchased from PeproTech (Rocky Hill, NJ, USA), and all other cytokines were obtained from R\&D Systems (Minneapolis, MN, USA). Anti-human IL-32 antibodies were purchased from R\&D Systems. All other reagents were purchased from Sigma Chemical Co. (St. Louis, MO, USA).

Culture of human colonic subepithelial myofibroblasts (SEMFS) and colonic epithelial cell lines. Primary colonic SEMF cultures were prepared according to the method reported by Mahida et al (21). The cellular characteristics and culture conditions were as described in our previous report (22). The human colon cancer cell line HT-29 was cultured as previously described (23).

Reverse transcription-polymerase chain reaction (RT-PCR) and real-time PCR. The expression of mRNA in the samples was assessed by RT-PCR and real-time PCR analyses. RT-PCR was performed according to methods described in our previous report (24). The oligonucleotide primers used in this study are shown in Table I. The different pairs of primers for specific IL-32 splice variants were designed using a particular intron and exon border, where a distinct splicing event takes place in each isoform $(8,25)$. Real-time PCR was performed using a LightCycler 2.0 system (Roche Applied Science, Tokyo, Japan). PCR was conducted using SYBR Green PCR Master Mix (Applied Biosystems, Foster City, CA, USA). Data were normalized to $\beta$-actin for human IL-32.

Cloning of the new IL-32 isoform and IL-32 $\gamma$ and transfection into HT-29 cells. Each PCR product for the new IL-32 isoform (336 bp), IL-32 $\alpha$ (396 bp) and IL-32 $\gamma$ (705 bp) was ligated into the BamHI and EcoRI restriction sites of the expression vector pIRESneo2 (Clontech Laboratories, Mountain View, CA). The expression vectors were transfected to HT-29 cells using FuGene HD (Roche Diagnostics K.K., Tokyo, Japan), and were selected by neomycin.

Tissue samples. The diagnosis of IBD was based on conventional clinical and endoscopic criteria. Biopsied specimens from 18 patients with UC ( 7 active, 11 inactive) and 15 patients with $\mathrm{CD}$ (10 active, 5 inactive) were used with informed consent. The ethics committee of the Shiga University of Medical Science approved the study. During the sample
A

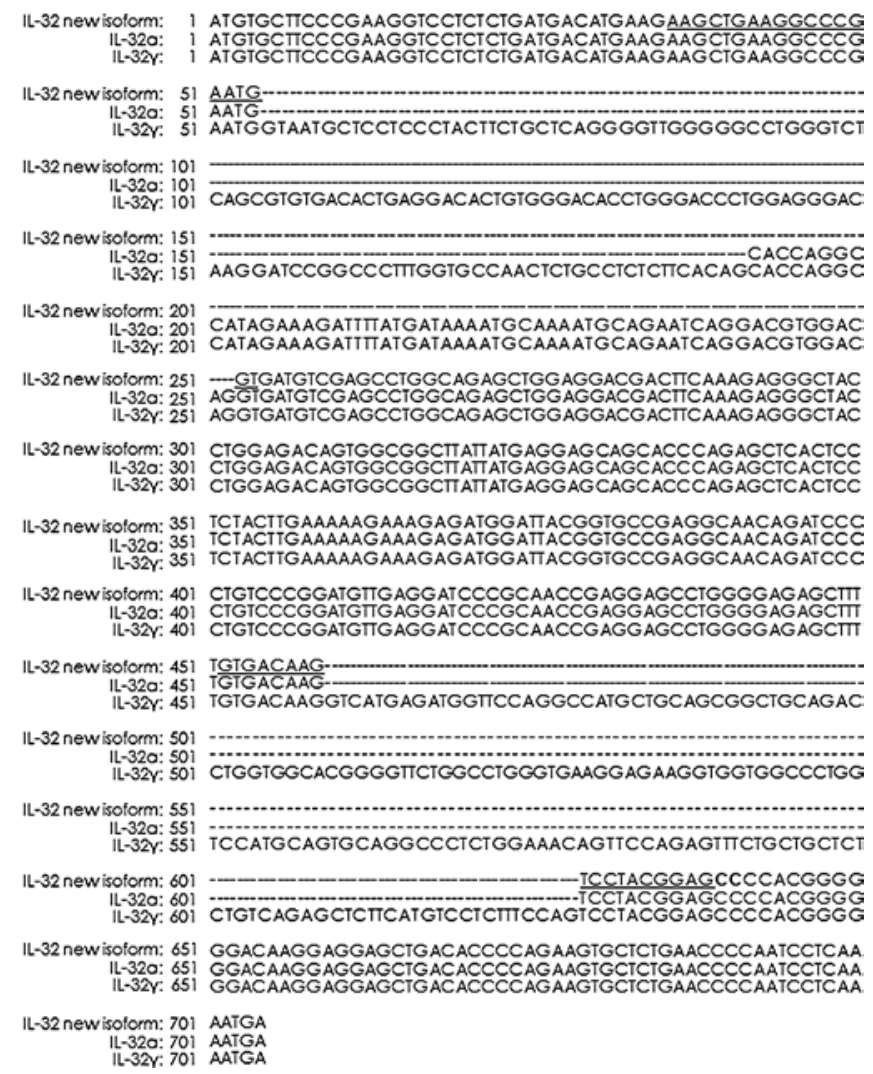

B

\begin{tabular}{|c|c|c|c|c|c|c|c|c|}
\hline IL32 new isoform: & 1 & & 3 & & 5 & 6 & & 8 \\
\hline IL-32a: & 1 & & 3 & 4 & 5 & 6 & & 8 \\
\hline IL-32ß: & 1 & & 3 & 4 & 5 & 6 & 7 & 8 \\
\hline IL-32y: & 1 & 2 & 3 & 4 & 5 & 6 & 7 & 8 \\
\hline IL-32б: & 1 & & 3 & 4 & & 6 & 7 & 8 \\
\hline IL-32ع: & 1 & 2 & 3 & & 5 & 6 & 7 & 8 \\
\hline
\end{tabular}

Figure 1. (A) Nucleotide sequence of the new isoform of IL-32, IL-32 $\alpha$ and IL-32 $\gamma(3,25)$. Underscore indicates the PCR primers for the IL-32 new isoform. (B) Schematic representation of the structures of the new isoform of IL-32 and previously reported IL-32 isoforms. Boxes indicate the exons of the IL-32 gene.

collection period, all patients were clinically and endoscopically active based on the colitis activity index for UC (26) and the Crohn's disease activity index (27). Histological examina- 
A

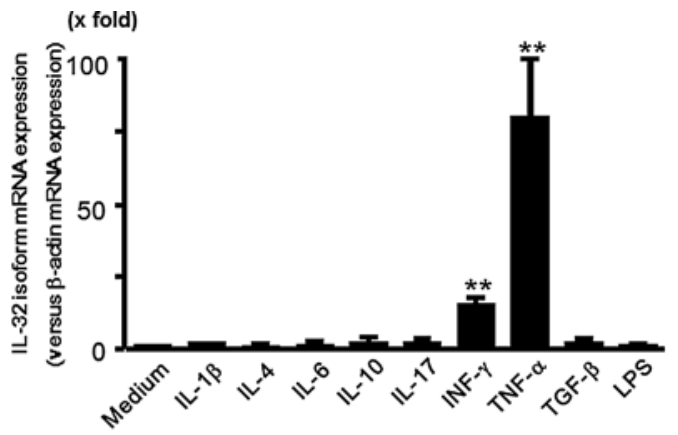

B

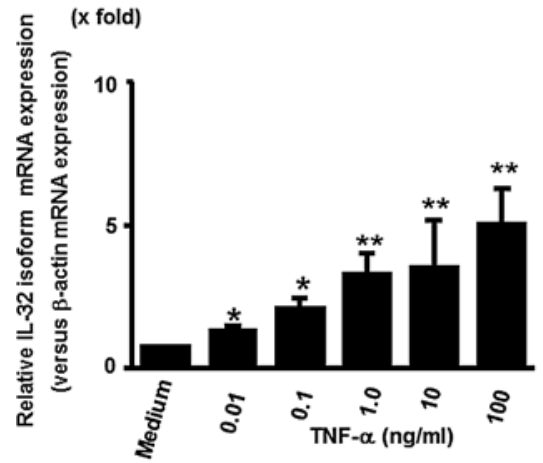

C

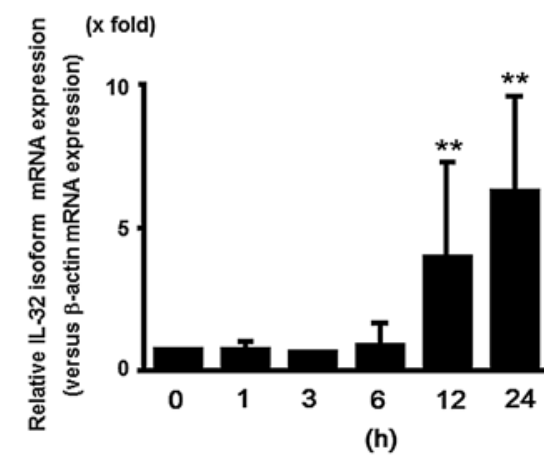

Figure 2. Regulation of the mRNA expression of the new IL-32 isoform in the colon cancer cell line HT-29. (A) HT-29 cells were stimulated with cytokines $(100 \mathrm{ng} / \mathrm{ml})$ for $12 \mathrm{~h}$. The mRNA expression of the new isoform was analyzed by real-time PCR. The mRNA expression of the new IL-32 isoform was expressed relative to the $\beta$-actin mRNA expression (mean $\pm \mathrm{SD}$ from four different experiments). ${ }^{*} \mathrm{P}<0.05,{ }^{* * *} \mathrm{P}<0.01$; significant difference compared to the values for medium alone. (B) Dose-dependent effects of TNF- $\alpha$ on the mRNA expression of the new IL-32 isoform. HT-29 cells were incubated for $12 \mathrm{~h}$ with increasing concentrations of TNF- $\alpha$. The mRNA expression levels of the new isoform were then determined by real-time PCR. Values are expressed as the means $\pm \mathrm{SD}(\mathrm{n}=5) .{ }^{*} \mathrm{P}<0.05,{ }^{* *} \mathrm{P}<0.01$; significant difference compared to the values for medium alone. (C) Time-dependent effects of TNF- $\alpha$ on the mRNA expression of the new IL-32 isoform. HT-29 cells were stimulated with TNF- $\alpha$ (100 ng/ml) for the pre-determined times. The mRNA expression levels of the new IL-32 isoform were determined by real-time PCR. Values are expressed as the means $\pm \mathrm{SD}(\mathrm{n}=5)$. ${ }^{*} \mathrm{P}<0.05,{ }^{* * *} \mathrm{P}<0.01$; significant difference compared to the values for medium alone.

tions were performed in macroscopically and microscopically non-affected and affected areas from each patient.

Statistical analysis. The statistical significance of the differences was determined by the Mann-Whitney U test (Statview Version 4.5). Differences resulting in P-values $<0.05$ were considered to be statistically significant.

\section{Results}

We isolated a new isoform of the IL-32 transcript (336 nucleotides) through the process of cloning the full-length IL-32 gene from human colonic SEMFs. The nucleotide sequences of this new isoform of the IL-32 transcript, IL-32 $\alpha$ and IL-32 $\gamma$, are shown in Fig. 1A $(3,25)$. The new isoform completely lacks exon 4, and is $60 \mathrm{bp}$ shorter than IL-32 $\alpha$ (Fig. 1B).

Previous studies have demonstrated that inflammatory stimuli induce IL-32 expression in various cell types $(1,18,28,29)$. To investigate the molecular mechanisms participating in the induction of the new isoform of the IL-32 gene, we evaluated the effects of various cytokines on the mRNA expression of the new isoform. TNF- $\alpha$ exerted a strong effect on the induction of the new isoform transcript in HT-29 cells (Fig. 2A). IFN- $\gamma$ also had modest, but significant, effects. The effects of TNF- $\alpha$ occurred in a dose- and time-dependent manner (Fig. 2B and 2C).

Previous studies have suggested that IL-32 plays a role as a cytoplasmic protein. To investigate the role of this new isoform of IL-32 in inflammatory responses, we constructed three different vectors expressing the new isoform of IL-32, IL-32 $\alpha$ or IL-32 $\gamma$, and investigated the effects of these constructs on TNF- $\alpha$-induced IL- 8 mRNA expression in HT-29 cells. As shown in Fig. 3, the empty pIRES vector had no effects, and TNF- $\alpha$ induced a marked increase in IL- 8 mRNA expression in HT-29 cells transfected with the empty pIRES vector. Transfection with the expression vector containing the new isoform of IL-32 significantly decreased TNF- $\alpha$-induced IL-8 mRNA, but transfection with the IL-32 $\alpha$ gene had no effects. Transfection with the expression vector containing the IL-32 $\gamma$ gene significantly reduced TNF- $\alpha$-stimulated IL- 8 mRNA expression, but its effects were much weaker than those induced by transfection with the new isoform of the IL-32 gene.

To evaluate the mRNA expression of the new isoform of IL-32 in the mucosa, mRNA expression for the new transcript was analyzed by real-time PCR in IBD mucosa. As shown in Fig. 4, real-time PCR analysis revealed a significant increase in the mRNA expression of the new isoform in samples from the active and inactive lesions of $\mathrm{CD}$ patients, as compared with samples from normal and inactive IBD mucosa.

\section{Discussion}

Based on sequence analysis, IL-32 does not belong to any established cytokine family, and many details of its biology remain elusive (3). Four isoforms of IL-32 exist due to alterna- 


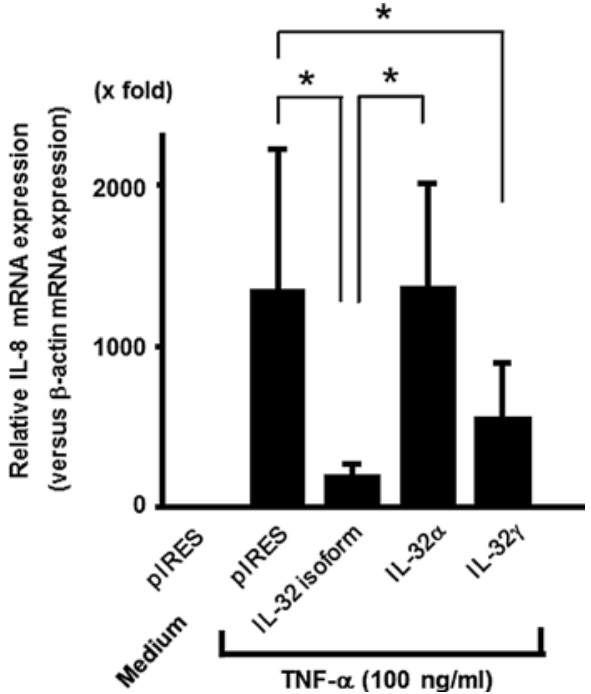

Figure 3. Effects of the stable transfection of the new IL-32 isoform gene on TNF- $\alpha$-induced IL- 8 mRNA expression in HT-29 cells. Three different vectors expressing the new isoform of IL-32, IL-32 $\alpha$ or IL-32 $\gamma$ were transfected into HT-29 cells. The cells were then stimulated with TNF- $\alpha(100 \mathrm{ng} / \mathrm{ml})$ for $12 \mathrm{~h}$, and their IL-8 mRNA expression was determined by real-time PCR. Values are expressed as the means $\pm \mathrm{SD}(\mathrm{n}=5) .{ }^{*} \mathrm{P}<0.05$; significant difference compared to the values for medium alone

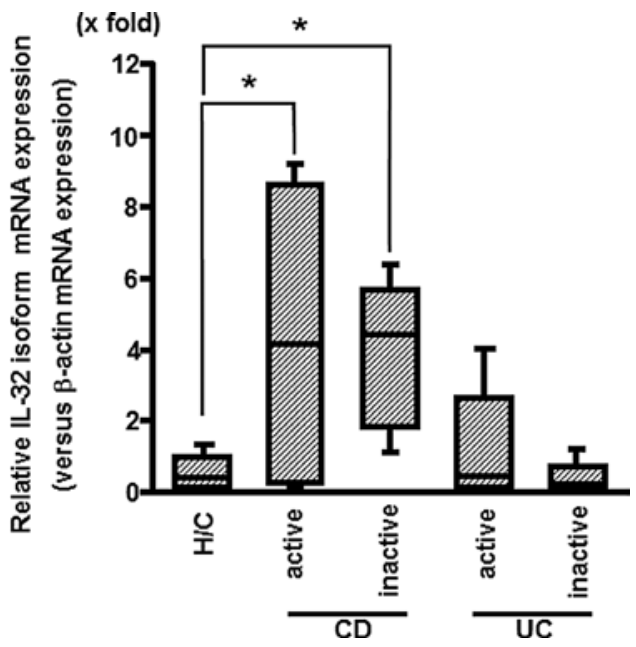

Figure 4. New IL-32 isoform mRNA expression in the IBD mucosa. Total RNA was extracted from biopsy samples, and the IL-32 isoform mRNA expression was evaluated by real-time PCR analyses. The data from the real-time PCR were normalized versus $\beta$-actin for the IL-32 isoform. The lower and upper margins of the box represent the 25th and 75th percentiles, with the bars representing the 10th and 90th percentiles, respectively. $\mathrm{H} / \mathrm{C}$, healthy control; CD, Crohn's disease; UC, ulcerative colitis. " $\mathrm{P}<0.05$.

tive mRNA splicing (2). In addition, two more IL-32 isoforms, $\varepsilon$ and $\zeta$, were recently reported; however, these two isoforms were not abundantly expressed in cell types besides activated $\mathrm{T}$ cells (5). The functions of each isoform, if they do indeed function in a unique manner, are not yet understood. IL-32 $\gamma$ contains a weak consensus signal sequence, suggesting that it may be a secreted protein (1). Other isoforms of IL-32 had no such signal sequence, but recombinant isoforms lacking the predicted signal sequence have been shown to be secreted (1). From the findings of previous studies, the secretion of IL-32 may be cell type or isoform specific, but multiple reports describing the induction of IL-32 have demonstrated an abundance of the protein in cellular lysates as opposed to supernatants $(5,18,29,30)$. The identification of a cell surface receptor for IL-32 may clarify whether IL-32 functions intracellularly or extracellularly.

In this study, we isolated a new isoform of the IL-32 transcript consisting of 336 nucleotides. This isoform completely lacks the 60 nucleotides of exon 4 of the IL- $32 \alpha$ gene, suggesting that it may represent a product of splice variants. Splice variants exist in other cytokines, such as IL-15 (31). Two IL-15 isoforms possess identical biological properties, and each one has a distinct regulation and expression pattern. The new IL-32 isoform presented in this study was dose- and time-dependently induced by TNF- $\alpha$. This was a similar response to the other isoforms of IL-32 $(18,28,29)$. Previously, we demonstrated that TNF- $\alpha$ is a potent stimulator of IL- $32 \alpha$ induction in HT-29 cells. In addition, IL-32 $\alpha$ mRNA expression in response to TNF- $\alpha$ was mediated by NF- $\kappa$ B. These findings suggest that TNF- $\alpha$ may stimulate the expression of the new IL-32 isoform through a signal transduction pathway mediated by NF- $\kappa \mathrm{B}$ activation. Previously, it was reported that TNF- $\alpha$ also induces NOD2 (32), which indicates a coupled regulation of IL-32 and NOD2. Since IL-32 and NOD proteins have been reported to act synergistically in the inflammatory response (2), a similar interaction of the new IL-32 isoform and NOD2 should be investigated in future.

Choi et al examined the biological activities of the four rIL-32 isoforms ( $\alpha, \beta, \gamma$ and $\delta$ ) with multiple bioassays (8). All four rIL-32 isoforms were biologically active and reacted with PR3. IL-32 $\gamma$, which is the longest isoform, exhibited the highest biological activity, inducing cytokines both in vitro and in vivo. In this study, the intracellular expression of the new IL-32 isoform exhibited a strong inhibitory effect on TNF- $\alpha$-induced IL- 8 mRNA expression. Similar effects were also observed for IL-32 $\gamma$. These obsevations suggest that the intracellular expression of the new IL-32 isoform has antiinflammatory actions. In addition, the inhibitory effects of the intracellular expression of IL-32 $\gamma$ suggest that IL-32 exerts different cellular responses via extracellular or intracellular receptors.

We previously demonstrated that the epithelial expression of IL-32 $\alpha$ was enhanced in the inflamed mucosa of IBD patients (18). Similarly, we observed that the mRNA expression of the new IL-32 isoform was significantly elevated in the inflamed mucosa of IBD patients. These observations suggest that the enhanced expression of the new IL-32 isoform plays a role in the inflammatory responses involved in the pathogenesis of IBD. Since the intracellular expression of the new IL-32 isoform exerted an anti-inflammatory effect in HT-29 cells, the enhanced mRNA expression observed in the new IL-32 isoform may have a protective effect against inflammation in the IBD mucosa.

We have identified a new isoform of the IL-32 transcript. Since the intracellular expression of this gene showed inhibitory effects on TNF- $\alpha$-induced IL-8 expression, it is possible that this new IL-32 isoform may have different intracellular and extracellular biological functions. Future studies on this new IL-32 isoform should provide further insights into the precise role of this novel transcript in the regulation of inflammatory responses. 


\section{References}

1. Kim SH, Han SY, Azam T, Yoon DY and Dinarello CA Interleukin-32: a cytokine and inducer of TNFalpha. Immunity 22: 131-142, 2005.

2. Netea MG, Azam T, Ferwerda G, et al: No. IL-32 synergizes with nucleotide oligomerization domain (NOD) 1 and NOD2 ligands for IL-1beta and IL-6 production through a caspase 1-dependent mechanism. Proc Natl Acad Sci USA 102: 16309-16314, 2005.

3. Dinarello CA and Kim SH: IL-32, a novel cytokine with a possible role in disease. Ann Rheum Dis 65 (Suppl 3): iii61-iii64, 2006.

4. Chen Q, Carroll HP and Gadina M: The newest interleukins: recent additions to the ever-growing cytokine family. Vitam Horm 74: 207-228, 2006.

5. Goda C, Kanaji T, Kanaji S, et al: Involvement of IL-32 in activation-induced cell death in T cells. Int Immunol 18: 233-240, 2006.

6. Kumar S, Hanning CR, Brigham-Burke MR, et al: Interleukin1F7B (IL-1H4/IL-1F7) is processed by caspase-1 and mature IL-1F7B binds to the IL-18 receptor but does not induce IFN-gamma production. Cytokine 18: 61-71, 2002.

7. Pufe T, Petersen W, Tillmann B and Mentlein R: The splice variants VEGF121 and VEGF189 of the angiogenic peptide vascular endothelial growth factor are expressed in osteoarthritic cartilage. Arthritis Rheum 44: 1082-1088, 2001.

8. Choi JD, Bae SY, Hong JW, et al: Identification of the most active interleukin-32 isoform. Immunology 126: 535-542, 2009.

9. Mayer L: Evolving paradigms in the pathogenesis of IBD J Gastroenterol 45: 9-16, 2010.

10. Podolsky DK: Inflammatory bowel disease. N Engl J Med 347: 417-429, 2002.

11. Hibi T and Ogata H: Novel pathophysiological concepts of inflammatory bowel disease. J Gastroenterol 41: 10-16, 2006.

12. Peyrin-Biroulet L, Vignal C, Dessein R, Simonet $M$, Desreumaux $\mathrm{P}$ and Chamaillard M: NODs in defence: from vulnerable antimicrobial peptides to chronic inflammation. Trends Microbiol 14: 432-438, 2006.

13. Hugot JP, Chamaillard M, Zouali $\mathrm{H}$, et al: Association of NOD2 leucine-rich repeat variants with susceptibility to Crohn's disease. Nature 411: 599-603, 2001.

14. Hugot JP: CARD15/NOD2 mutations in Crohn's disease. Ann NY Acad Sci 1072: 9-18, 2006.

15. Netea MG, Ferwerda G, De Jong DJ, et al: Nucleotide-binding oligomerization domain-2 modulates specific TLR pathways for the induction of cytokine release. J Immunol 174: 6518-6523, 2005.

16. Netea MG, Kullberg BJ, De Jong DJ, et al: NOD2 mediates antiinflammatory signals induced by TLR 2 ligands: implications for Crohn's disease. Eur J Immunol 34: 2052-2059, 2004.

17. Maeda S, Hsu LC, Liu H, et al: Nod2 mutation in Crohn's disease potentiates NF-kappaB activity and IL-1beta processing Science 307: 734-738, 2005.
18. Shioya M, Nishida A, Yagi Y, et al: Epithelial overexpression of interleukin-32alpha in inflammatory bowel disease. Clin Exp Immunol 149: 480-486, 2007.

19. Kobori A, Yagi Y, Imaeda H, et al: Interleukin-33 expression is specifically enhanced in inflamed mucosa of ulcerative colitis. J Gastroenterol 45: 999-1007, 2010.

20. Hasegawa H, Thomas HJ, Schooley K and Born TL: Native IL-32 is released from intestinal epithelial cells via a nonclassical secretory pathway as a membrane-associated protein. Cytokine 53: 74-83, 2010.

21. Mahida YR, Beltinger J, Makh S, et al: Adult human colonic subepithelial myofibroblasts express extracellular matrix proteins and cyclooxygenase-1 and -2. Am J Physiol 273: G1341-G1348, 1997.

22. Okuno T, Andoh A, Bamba S, et al: Interleukin-1beta and tumor necrosis factor-alpha induce chemokine and matrix metalloproteinase gene expression in human colonic subepithelial myofibroblasts. Scand J Gastroenterol 37: 317-324, 2002.

23. Zweibaum A, Pinto M, Chevalier G, et al: Enterocytic differentiation of a subpopulation of the human colon tumor cell line HT-29 selected for growth in sugar-free medium and its inhibition by glucose. J Cell Physiol 122: 21-29, 1985.

24. Andoh A, Takaya H, Saotome T, et al: Cytokine regulation of chemokine (IL-8, MCP-1, and RANTES) gene expression in human pancreatic periacinar myofibroblasts. Gastroenterology 119: 211-219, 2000.

25. Dahl CA, Schall RP, He HL and Cairns JS: Identification of a novel gene expressed in activated natural killer cells and T cells. J Immunol 148: 597-603, 1992

26. Rachmilewitz D: Coated mesalazine (5-aminosalicylic acid) versus sulphasalazine in the treatment of active ulcerative colitis: a randomised trial. BMJ 298: 82-86, 1989.

27. Best WR, Becktel JM and Singleton JW: Rederived values of the eight coefficients of the Crohn's Disease Activity Index (CDAI). Gastroenterology 77: 843-846, 1979.

28. Nishida A, Andoh A, Shioya M, Kim-Mitsuyama S, Takayanagi A and Fujiyama Y: Phosphatidylinositol 3-kinase Akt signaling mediates interleukin-32alpha induction in human pancreatic periacinar myofibroblasts. Am J Physiol Gastrointest Liver Physiol 294: G831-G838, 2008.

29. Nishida A, Andoh A, Inatomi O and Fujiyama Y: Interleukin-32 expression in the pancreas. J Biol Chem 284: 17868-17876, 2009.

30. Kobayashi H and Lin PC: Molecular characterization of IL-32 in human endothelial cells. Cytokine 46: 351-358, 2009.

31. Tagaya Y, Kurys G, Thies TA, et al: Generation of secretable and nonsecretable interleukin 15 isoforms through alternate usage of signal peptides. Proc Natl Acad Sci USA 94: 14444-14449, 1997.

32. Rosenstiel P, Fantini M, Brautigam K, et al: TNF-alpha and IFN-gamma regulate the expression of the NOD2 (CARD15) gene in human intestinal epithelial cells. Gastroenterology 124: 1001-1009, 2003. 